\title{
Application of ANN for analysing a neighbourhood of single-family houses constituting an Energy Cluster
}

\author{
Marcin Zygmunt ${ }^{1, *}$, and Dariusz Gawin ${ }^{1}$ \\ ${ }^{1}$ Lodz University of Technology, Faculty of Civil Engineering, Architecture and Environmental \\ Engineering, Lodz, Poland
}

\begin{abstract}
In this article a simple computer tool that can predict energy demand of residential buildings area in Poland by means of artificial neural network is developed and its application is demonstrated. Authors focused on energy demand analyses for single-family houses, representative for the Polish household sector. Advanced computer simulations were performed by means of the Energy Plus software, with hourly calculation step. Then, the obtained results and simulation parameters were used as input data for artificial neural network analysis. As a result, authors developed a simple, user friendly computer tool that can predict, with relatively good accuracy in comparison to the Energy Plus results, energy demand for residential buildings located in Poland. The software might be used for local (a single building) or regional (whole areas, neighbourhoods) analyses of singlefamily houses in Polish household sector. Additionally, for the analysed area, Renewable Energy potential can be checked - the developed software allows for analyses of solar energy application in the building / neighbourhood design. Some examples of the energy analyses performed by means of the developed software have been presented.
\end{abstract}

\section{Introduction}

Energy efficiency is one of the most important factors according to global strategies concerning sustainability. Building sector is responsible for approx. $40 \%$ of global energy consumption and around $20 \%$ of greenhouse gas emissions. In Poland, household sector consists mainly of single-family houses, which in most of the cases require thermomodernisation to improve their energy efficiency. Authors considered, that nowadays, the energy and economical effect of such retrofitting should be evaluated with advanced energy simulations. Computer simulations, performed with at least hourly calculation period, are able to describe better the dynamics of heat transfer via building enclosure, air leakages, facilities parameters, time schedules and impact of outdoor environment [1-3] beside Polish standard building energy certification methodology.

The article focuses on energy demand analysis for a neighbourhood consisting of singlefamily houses representative for Poland. Our main aim is to create a simple computer tool

\footnotetext{
${ }^{*}$ Corresponding author: marcin.zygmunt@p.lodz.pl
} 
able to predict energy profile and to map energy characteristics of the analysed area. The software uses artificial neural network (ANN) to predict energy demand profile of an analysed single building or considered area (e.g. energy cluster). The built-in database consists of results from the Energy Plus simulations and might be expanded anytime. Some analyses of solar energy application can be performed using the developed software as well.

\section{Analysis description}

The Polish household sector was selected as a subject of analysis, due to its size and impact on energy demand in Poland. According to the published data about Polish building typology [4], 7 computer models of representative single-family houses were defined in the Energy Plus software. In total, 6720 parametric simulations were performed, with different combination of the following parameters: weather data (TMY format), insulation thickness of building envelope, coefficient of performance (COP) of the heating stove, overall Uvalue for windows. The next step was to perform the neural network analysis (see section 2.1), including testing the trained ANN with some additional data (see section 2.2). After finishing the analysis, all gathered results were used as the database for the software, which allows to perform energy analyses for a larger area (e.g. Energy Cluster). Within the software, solar energy analysis is included. The developed software considers building orientation and impact of its' nearest surrounding (positioning). Using the developed tool, it is possible to obtain several useful outputs for Energy Cluster analysis (see section 3). The developed tool is codded in the Python programming language incorporates Maple software (ANN analysis) and a csv-type files (database storages). The analysis procedure flowchart is graphically presented in Fig. 1.



Fig. 1. The analysis procedure scheme

\subsection{Artificial Neural Network analyses}

In recent years ANNs have been successfully used within many complex scientific and industrial applications [5-7]. The ANNs, inspired by human nervous system, may perform a kind of black box analysis - it is possible to define problem using only the 'input and output' information, without detailed knowledge about a system internal structure and functioning [8,9]. ANNs have proved to be a universal approximator - they can be successfully used for solving various multi-variable problems, including optimization.

The aim of the presented ANN analysis is to predict a heating demand for a singlefamily house considering its main characteristics. For the performed analysis LevenbergMarquardt (LM) method [10] (also known as the damped least-squares method) has been used. The selected method is based on gradient vector and Jacobian matrix - it might be considered as a combination of the Newton and the gradient descent methods. The neural network training process was divided into 3 different parts, depending on the input data calculation periods (monthly, daily and hourly). The structure of the ANN contains only one hidden layer with 12 neurons within it - the different number of hidden neurons have been checked, starting with 2 and ended with 24, following the procedure [11]. The network structure includes 10 input neurons and 1 output neuron - selected to provide the best data regression balanced with reasonable calculation time for the used input and output data. In total, 80640,2452800 and 58867200 rows of data were used, accordingly for monthly, daily and hourly analyses. 
As an input data the following parameters have been used: the analysis time period [months; days; hours] (depending on the analysis type), outside temperature $\left[{ }^{\circ} \mathrm{C}\right]$, total sun radiation $\left[\mathrm{Wh} / \mathrm{m}^{2}\right]$, heated area $\left[\mathrm{m}^{2}\right]$ and volume $\left[\mathrm{m}^{3}\right]$ of a building, total windows area $\left[\mathrm{m}^{2}\right]$, air-change rate (sum of the ventilation and infiltration values) $[1 / \mathrm{h}]$, U-value of external walls $\left[\mathrm{W} / \mathrm{m}^{2} \mathrm{~K}\right], \mathrm{U}$-value of windows $\left[\mathrm{W} / \mathrm{m}^{2} \mathrm{~K}\right]$ and heating stove COP $[-]$ while the output data included heating demand $[\mathrm{kW}]$. All input and output data were divided into 3 types of samples: training, validation and testing set, containing 70,15 and $15 \%$ of the data, respectively.

Training results can be seen in Fig. 2. - graphs present regression plots for the test group of samples (for each calculation period) for the learning data used. For monthly and daily periods analysis, we can observe very good prediction (test data regression coefficient $R$ equals to 0.9958 and 0.9808 , accordingly) and a good one for hourly study $(R=0.8903)$.
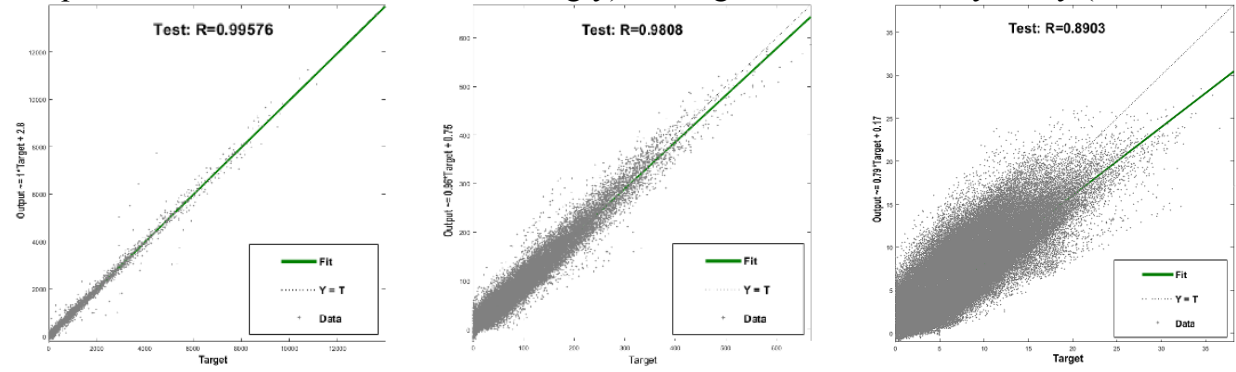

Fig. 2. Regression plots for the test data of neural network analysis for different calculation periods: monthly (left), daily (middle) and hourly (right).

\subsection{Validation of trained ANNs}

The performed validation process of the trained network was divided into two parts. Firstly, a modified computer model of a single-family house was defined (it is based on one of the previously defined building models). For the validation purpose, 5 different variants were checked using the Energy Plus simulations to generate reference output values. The validation was performed using the weather data of Warsaw, which is different location than used during ANN learning process. For the weather data used, both temperature and total solar radiation values stayed within ANN training input data range. The considered variants consisted of different combinations of listed parameters: heating stove COP (0.86), insulation layer thickness $(0.11 \mathrm{~m})$, different building shape (heating area and volume).

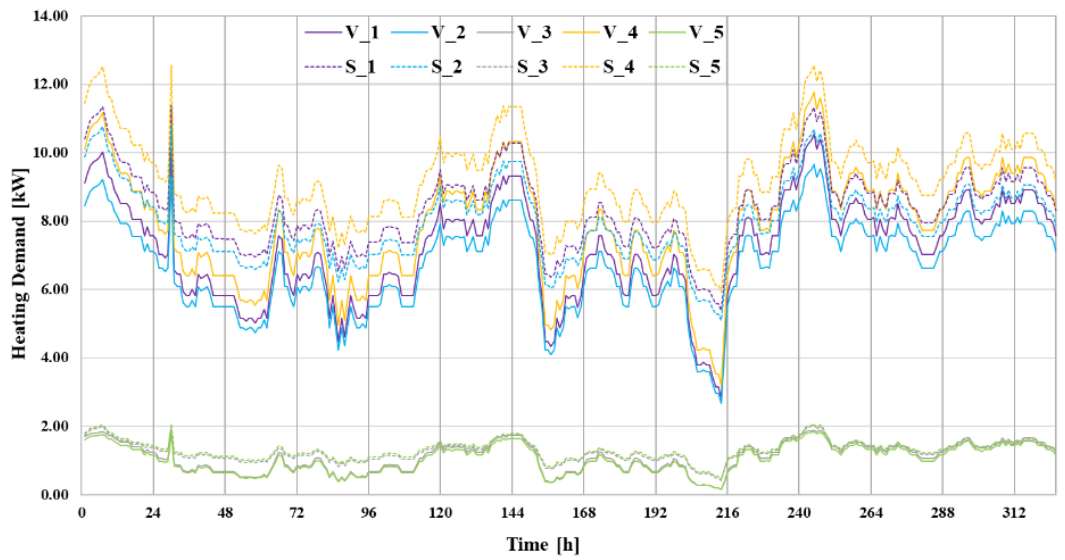

Fig. 3. Collation of the hourly heating demand values comparison between results obtained using the Energy Plus simulations ("S" data, dashed line) and ANN predictions ("V" data, solid line) 
Secondly, the new input data set was used to predict heating demand using ANNs. In Fig. 3 the comparison of the ANNs and Energy Plus results for hourly outputs has been shown. Plot presents results for an exemplary 2 weeks period, where " $V$ " stands for the ANN results and " $S$ " is Energy Plus simulation outputs.

For monthly period, the maximum difference between the values predicted by ANNs and the calculated ones was about 19\%. Annual heating consumption difference varied from $2 \%$ up to $15 \%$, depending on the test variant. For daily period the maximum difference was equal to $28 \%$, while annual heating demand value differences fluctuated between $1 \%$ and $9 \%$. The hourly period test runs resulted with maximum difference of $65 \%$ between the predicted and calculated values. The highest differences are observed for the variants with changed building geometry. Within whole input data for NN training process, only 7 different pairs of geometry parameters were used - that is a probable reason, why the network was not so accurate in that case. Annual heating consumption difference varies from $2 \%$ up to $14 \%$. For purposes of the performed Energy Cluster analysis this is a sufficient accuracy of a single building energy consumption prediction - the main effort is focused at analysing energy efficiency increase globally (i.e. for the whole area).

\section{Results of the Energy Cluster analysis}

The developed software might be used for analysing energy efficiency of thermal retrofit strategies and energy demand of a single building and at larger scale (neighbourhoods, cities, states) for Polish single-family household sector, with a good prediction accuracy. The developed tool allows defining easily the neighbourhood and presenting/collating energy analysis outputs. The code uses built-in database, in order to find the proper simulation variants and its' results. It is possible to perform several useful energy analyses, e.g. the heating demand, electricity consumption, solar energy production by PV systems or load duration curve for a considered area.

The first step of the energy cluster analysis is to define size of the analysed area, i.e. the length and width expressed in numbers of houses. It was assumed, that each house land stands for a squared area (here $30 \mathrm{~m} \times 30 \mathrm{~m}$ ) and building is located directly in its centre. Next, user should assign each building to a proper spot within the analysed neighbourhood by defining its main building parameters (i.e. area, volume, orientation etc.). Each variant is assigned by its unique number, generated referring to the building and variant parameters. The impact of the building orientation and its' closest surrounding on energy consumption is considered- the final output value expresses the actual building position. Additional data, e.g. collected during ANN analysis, might be included within the software database anytime. Moving forward, user decides, what kind and in what form results are received by default the code generates outputs as maps. Finally, after receiving the base outputs, user might select to generate additional results, including energy efficiency improvement variants of the analysed region or for some chosen buildings.

Renewable energy analysis, including the solar energy production by PV microinstallations, was calculated by the software for the considered area. Within PV production analysis a well-known solar energy methodology was used [12]. Numbers of PV panels were defined considering their appropriate placement in the available area within one roof slope - in total, solar microgrid might covered up to $40 \%$ of total roof area. Moreover, the PV panels inclination and orientation were assumed equal to a pitched roof geometry (30 degrees) and building orientation (8 main directions). The characteristics of the used PV modules were defined according to $[13,14]$.

In Fig. 4 some exemplary results obtained by means of the developed software are presented. The analysis concerns the neighbourhood of randomly selected 2500 single- 
family houses (50x50 property sized area). The results are presented as maps of different energy related characteristics of the analysed neighbourhood:

- the heating demand before and after the modernisation (Figs. 4a and 4b),

- the electricity consumption for the base variant with scenario assuming replacing traditional lightbulbs with LEDs (Figs. 4c and 4d),

- the total $\mathrm{CO}_{2}$ emissions in the analysed area for the base variant and after the modernization (Figs. 4e and 4f)
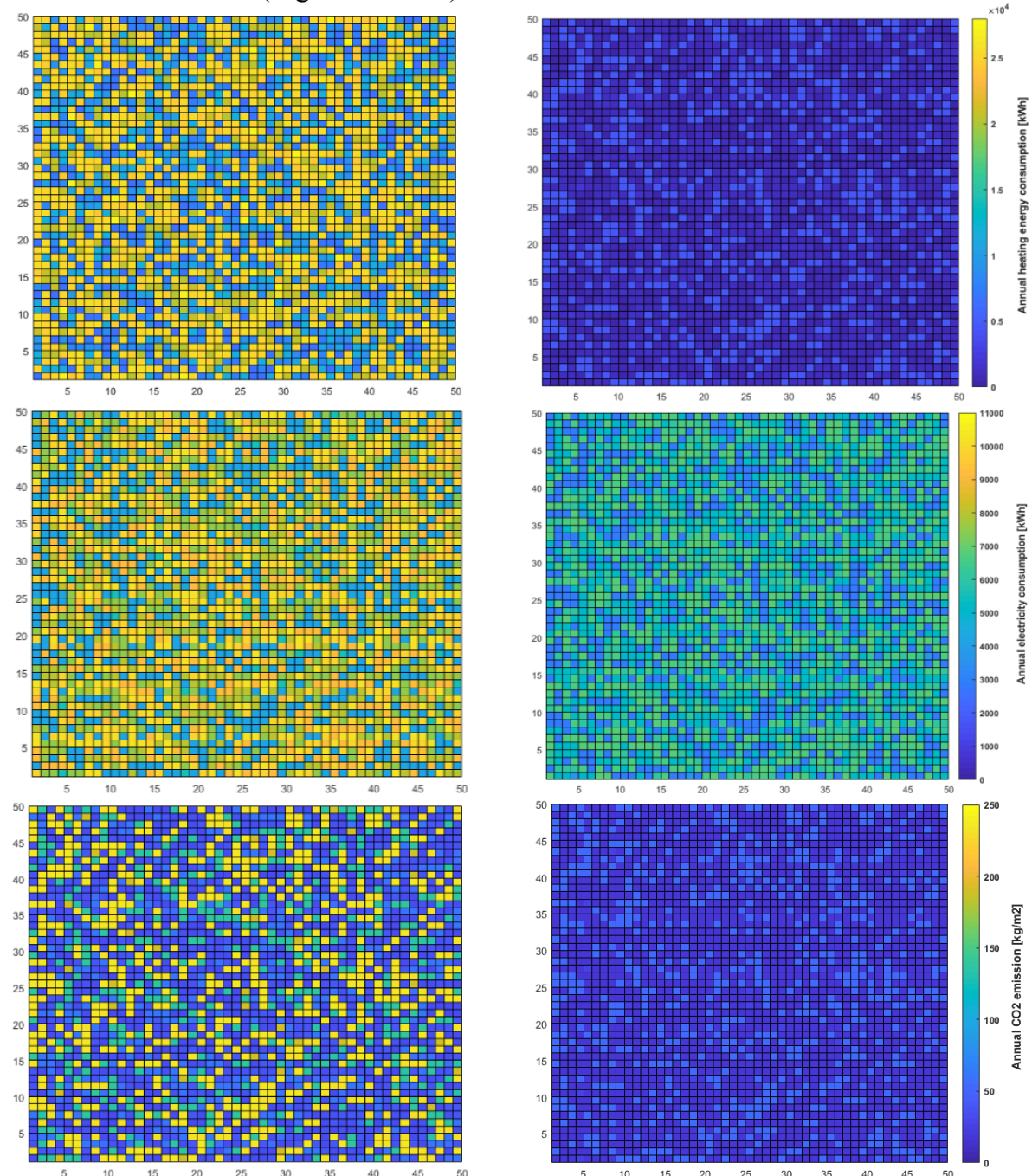

Fig. 4. The result maps for the analysed neighbourhood: a) Heating energy consumption - base variant (left-top); b) Heating energy consumption after thermal renovation (right-top); c) Electricity consumption - base variant (middle-left); d) Electricity consumption with LEDs (middle-right); e) Annual $\mathrm{CO}_{2}$ emission - base variant (left-bottom); f) Annual $\mathrm{CO}_{2}$ emission after thermal renovation (right-bottom)

\section{Summary}

The developed software might be a helpful computer tool for energy analyses of the Polish household sector. The tool uses appropriately defined and trained ANN which gives as 
output energy demand predictions, which are characterized by good accuracy referring to the Energy Plus simulation results. The developed software gives flexibility in presenting results of various energy related analyses. Using the software, it is possible, to perform various advanced analysis for some larger areas (e.g. Energy Clusters), including renewable energy usage/production. The tool might be improved by adding some extensions, e.g. economic analysis.

The neural network allows to predict heating energy demand with a sufficient accuracy for the parameters within the input data range used during training (e.g. unknown weather data).

Within the further research, authors plan further development of the software in order to obtain a universal, easy to use computer tool for analysing the Polish household sector energy by means of artificial intelligence techniques.

\section{References}

1. I. Vigna, R. Pernetti, W. Pasult, R. Lollini, New domain for promoting energy efficiency: Energy Flexible Building Cluster, Sustainable Cities and Society (2018)

2. X. Zhang, M. Lovati, I. Vigna, J. Widen, M. Han, C. Gal, T. Feng, A review of urban energy systems at building cluster level incorporating renewable-energy sources (RES) envelope solutions, Applied Energy (2018)

3. Z. Wei, W. Xu, D. Wang, L. Li, L. Niu, W. Wang, B. Wang, Y. Song, A study of citylevel building energy efficiency benchmarking system for China, Energy \& Buildings (2018)

4. National Energy Conservation Agency, Polish Building Typology - Scientific Report, Warsaw (2012)

5. C. Buratti, M. Barbanera, D. Palladino, An original tool for checking energy performance and certification of buildings by means of artificial neural network, Applied Energy (2014)

6. A. Lazrak, A. Leconte, D. Cheze, G. Fraisse, P. Papillon, B. Souyri, Numerical and experimental results of a novel and generic methodology for energy performance evaluation of thermal systems using renewable energies, Applied Energy (2015)

7. J. Pascual, J. Barricarte, P. Sanchis, L. Marroyo, Energy management strategy for a renewable-based residential microgrid with generation and demand forecasting, Applied Energy (2015)

8. G. Dreyfus, Neural network methodology and applications, Springer (2005)

9. M. Lefik, Application of artificial neural networks in mechanics and in engineering, TUL Publishers (2005)

10. D. Marquardt, An Algorithm for Least-Squares Estimation of Nonlinear Parameters, Journal of the Society for Industrial and Applied Mathematics (1963)

11. D. Stathakis, How many hidden layers and nodes? International Journal of Remote Sensing (2008)

12. G. N. Tiwari, A. Tiwari, Shyam, Handbook of Solar Energy. Theory, Analysis and Applications, Springer (2016)

13. P. Gagon, R. Margolis, J. Melius, C. Phillips, R. Elmore, Rooftop Solar Photovoltaic Technical Potential in the United States: A Detailed Assessment, National Renewable Energy Laboratory (2016)

14. International Technology Roadmap for Photovoltaic - Results 2017, (2018) 